\title{
Monosodium Urate Crystal Measurement
}

National Cancer Institute

\section{Source}

National Cancer Institute. Monosodium Urate Crystal Measurement. NCI Thesaurus.

Code C74681.

The determination of the amount of monosodium urate crystals present in a sample. 